\title{
Long Hole Film Cooling Dataset for CFD Development - Flow and Film Effectiveness
}

Vikram Shyam, Doug Thurman, Phil Poinsatte, Ali Ameri

50th AIAA/ASME/SAE/ASEE Joint Propulsion Conference

July 28, 2014 Cleveland, $\mathrm{OH}$ 


\section{Outline}

- Background

- Setup of Experiment

- Thermocouple and Hotwire

- Infrared Thermography

- Setup of Computations

- Results (more results in paper)

$-\mathrm{M}=0.5$

$-M=1.0$

$-\mathrm{M}=2.0$

- Comparison to literature

- Conclusions 


\section{Background}
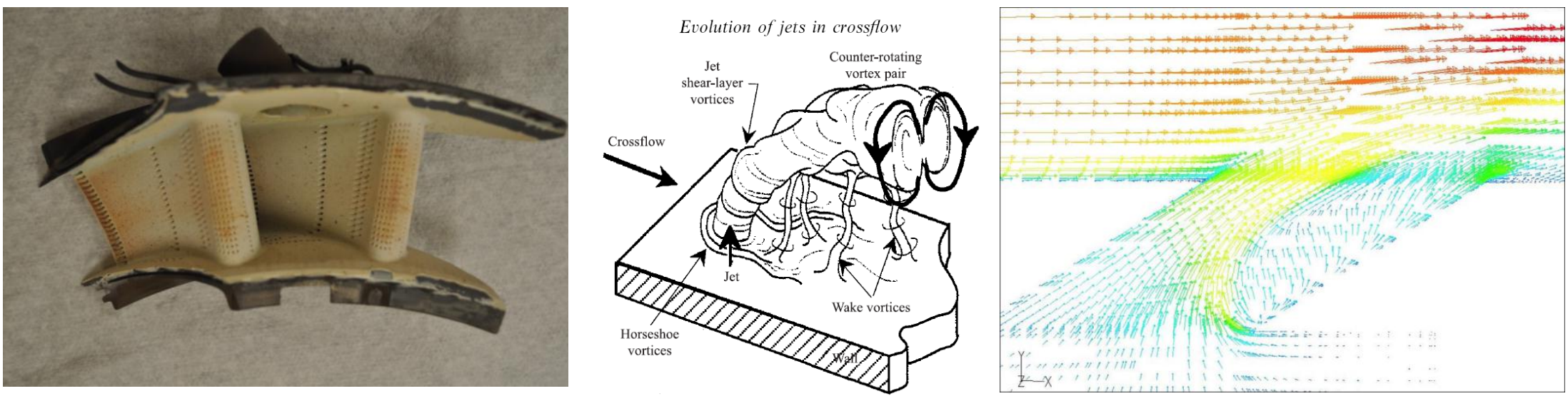

- Want simple dataset for CFD validation

- No effect of plenum

- No effect of hole length to diameter ratio (L/D) - fully developed pipe flow

- Multiple measurement methods - IR, thermocouple

- Single gas mixing

- Large holes for detailed measurements

- Existing IR thermography data not consistent (Comparisons shown in paper.) 


\section{Setup of Experiment}
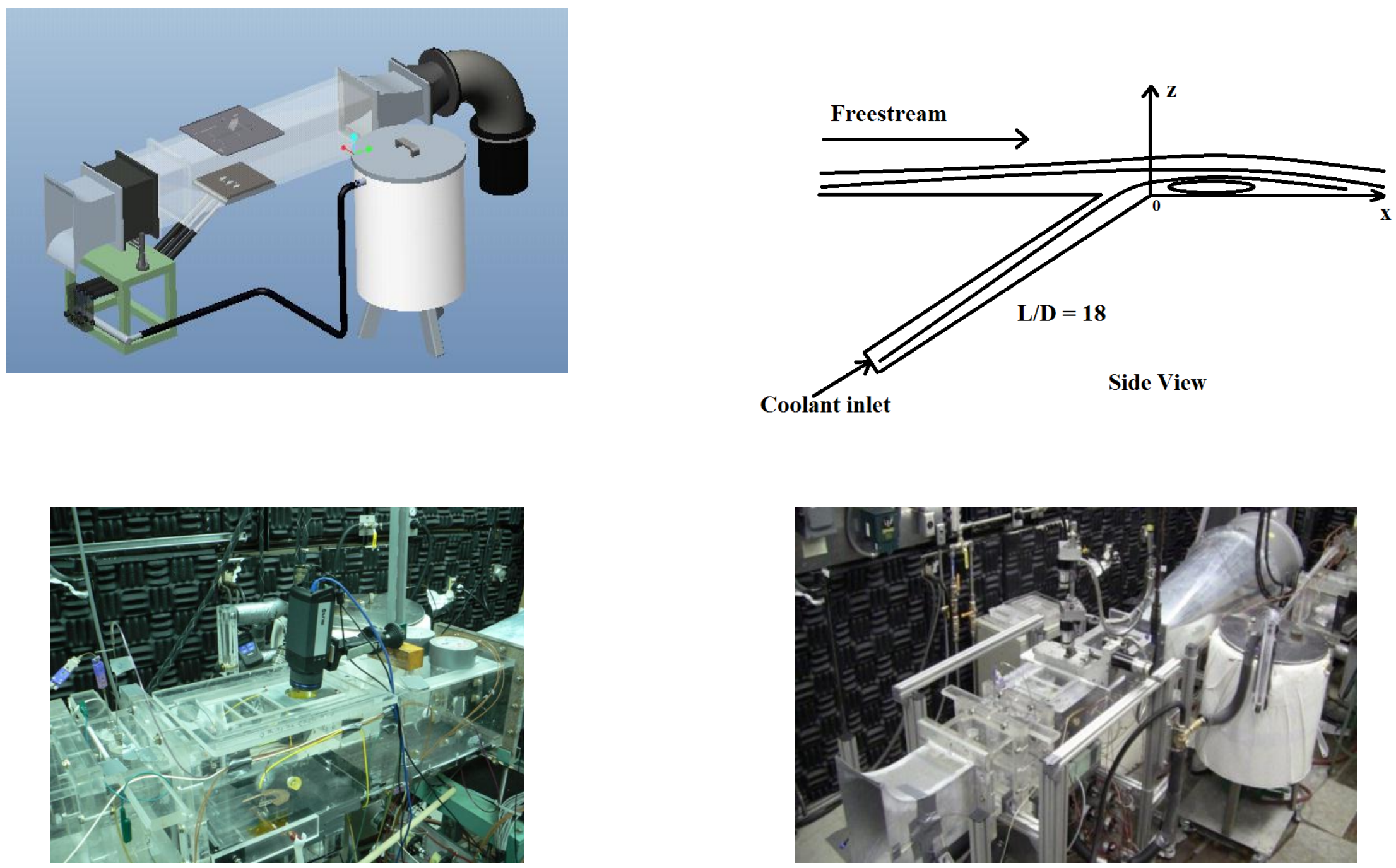
Setup of Experiment - Thermocouple and Hotwire

- Centerline survey

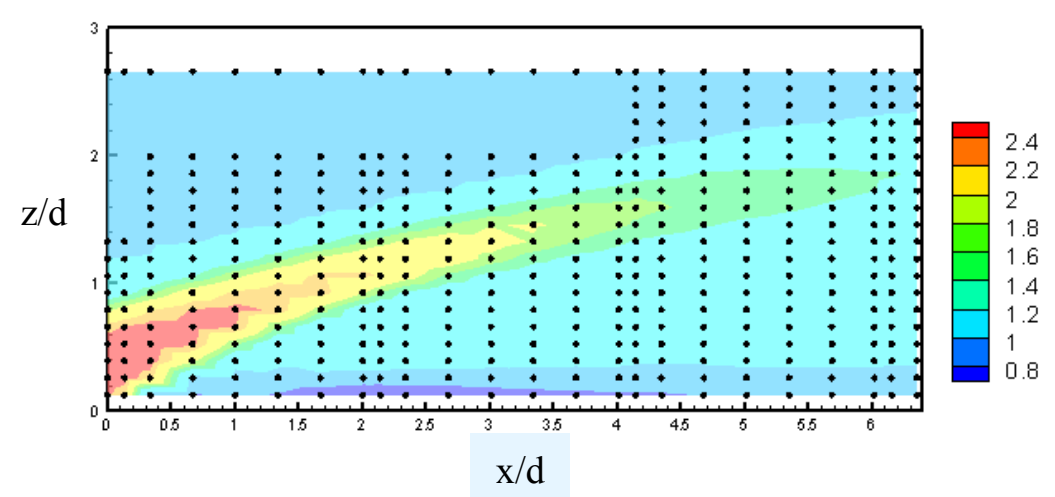

- Span-wise survey at 4 planes $-x / d \sim 0,2,4,6$.

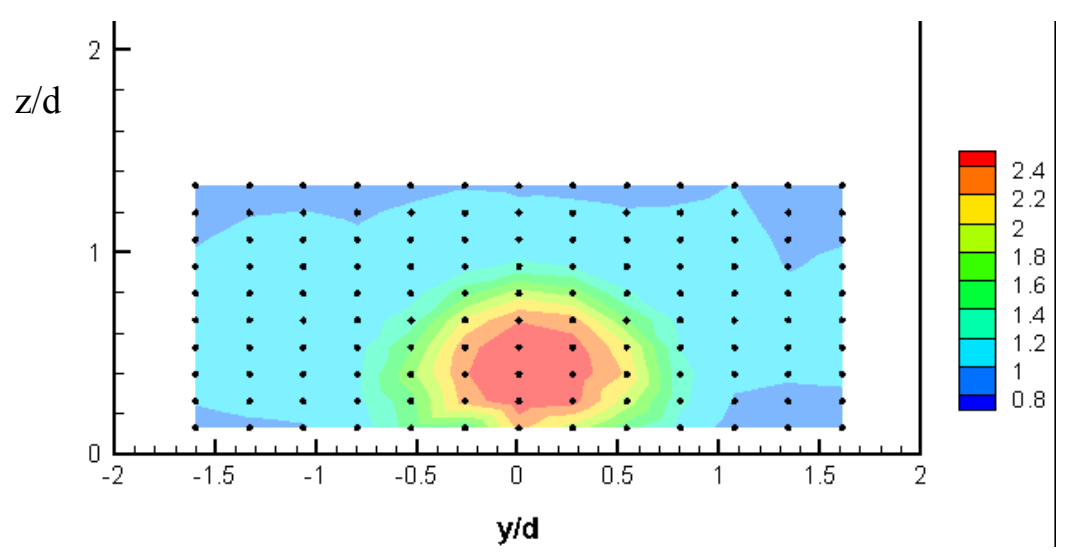


National Aeronautics and Space Administration

\section{Setup of Experiment - Infrared Thermography}

$\eta_{\text {methodl }}=\frac{T_{\mathrm{rec}}-T_{a w}}{T_{\mathrm{rec}}-T_{c}}$

$\eta_{\text {method2 }}=\frac{T_{\infty}-T_{a w}}{T_{\infty}-T_{c}}$

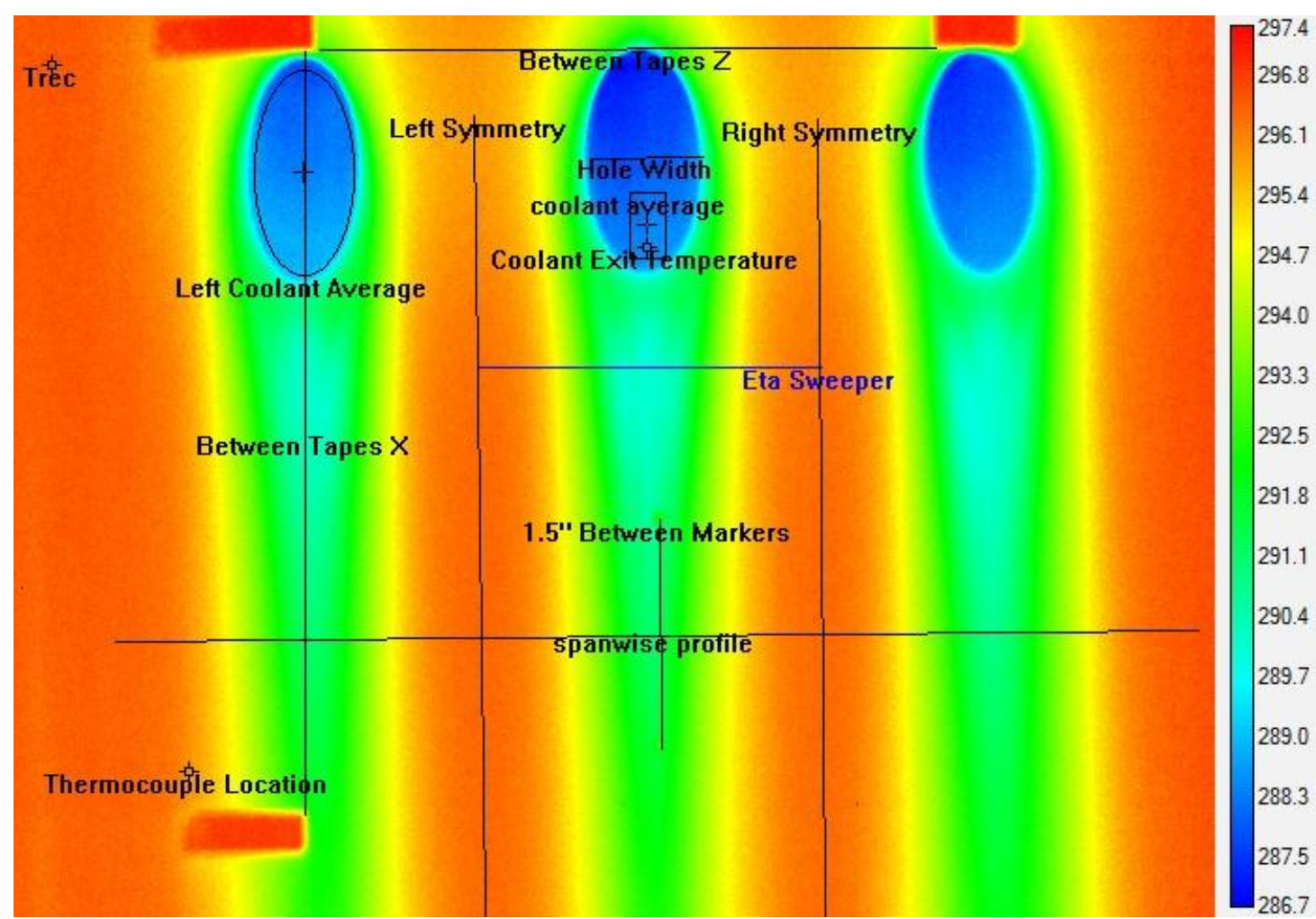




\section{Setup of Computations}

- NASA Glenn-HT code using TFNS (VLES/PRNS)

- 1200 Nodes

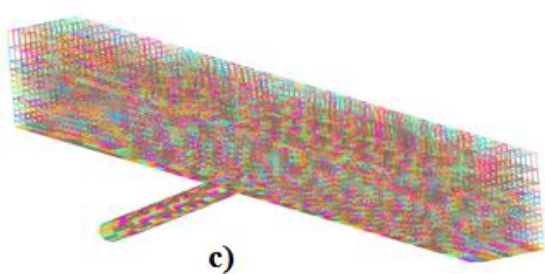

c)

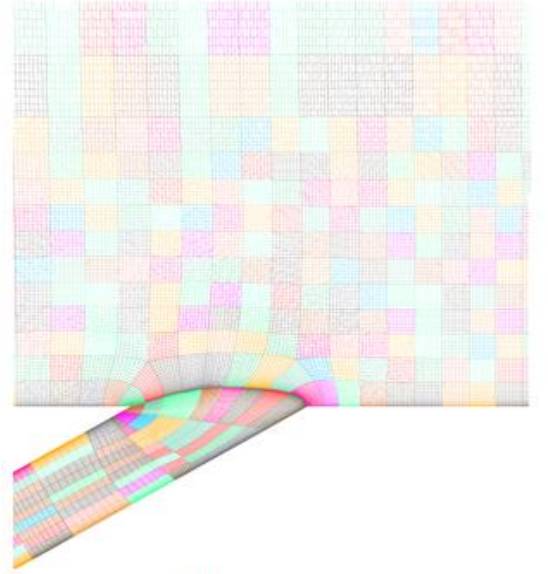

a)

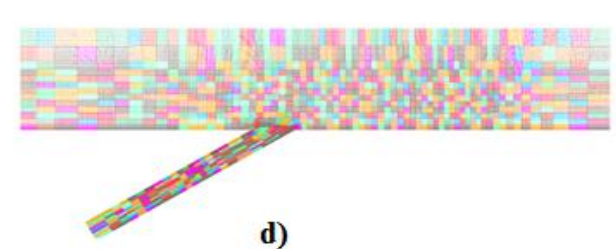

d) 


\section{Results}

- Blowing ratios $(\mathrm{M})-0.5,1.0,1.5,2.5$

- Density ratio - 1.0

- Reynolds no. (hole diameter and free stream velocity)

$-11,000$. Matches engine conditions

- Turbulence intensity $-1.5 \%$ and $8 \%$ (IR only) 


\section{Effectiveness Results $-\mathrm{M}=0.5$}
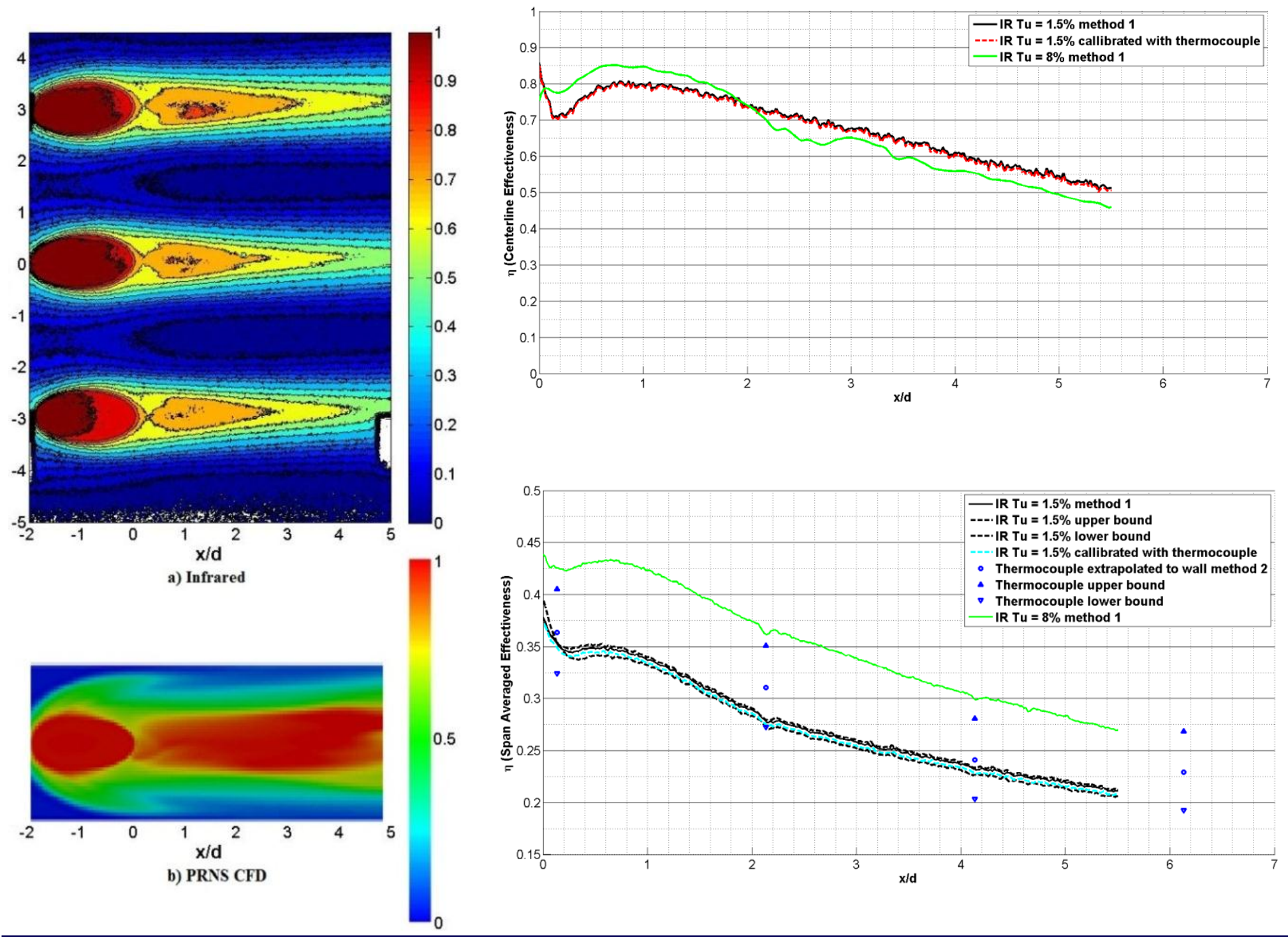


\section{Flowfield Results (CFD) $-M=1.0$}

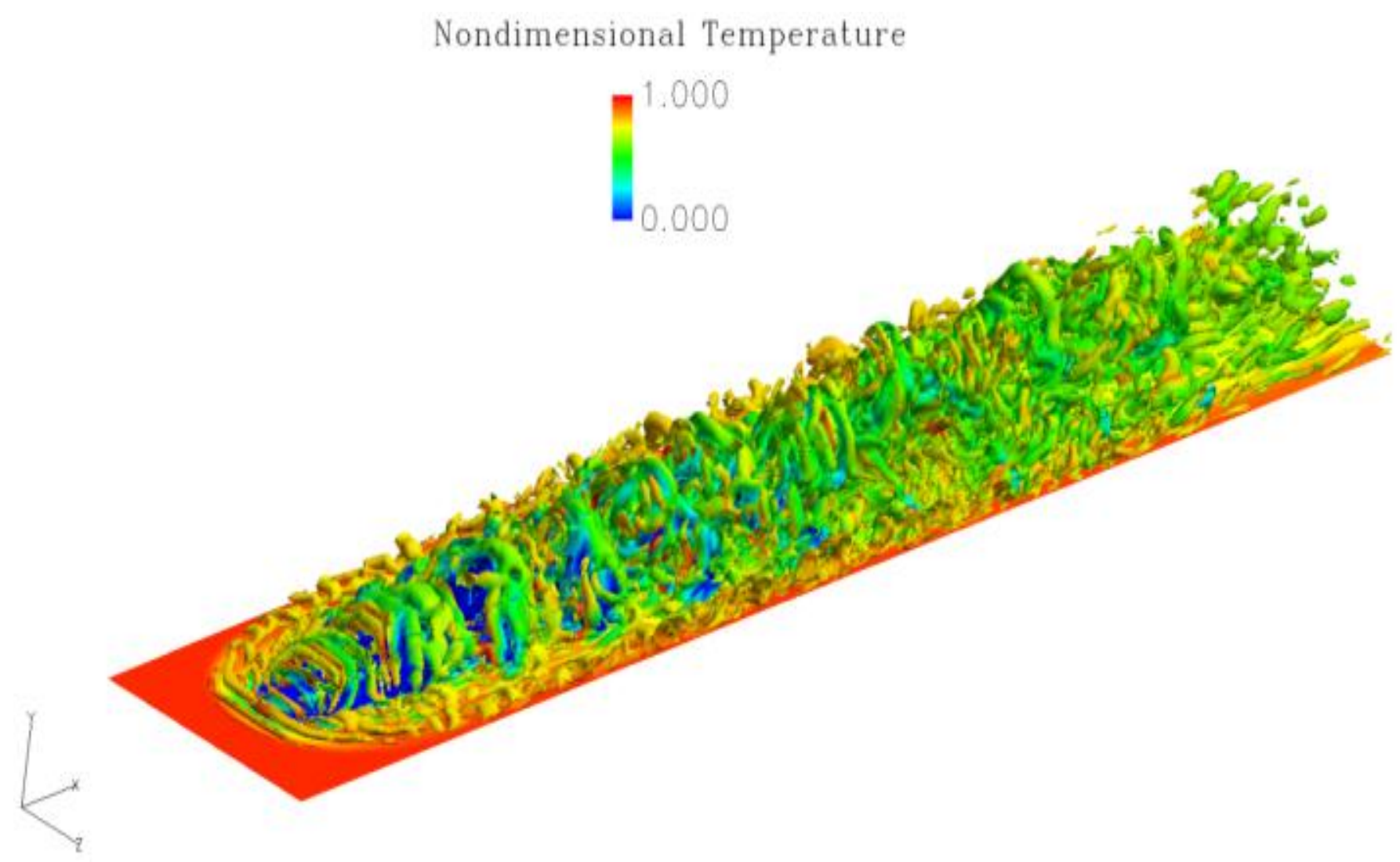




\section{Effectiveness Results $-M=1.0$}

$n$ effectiveness

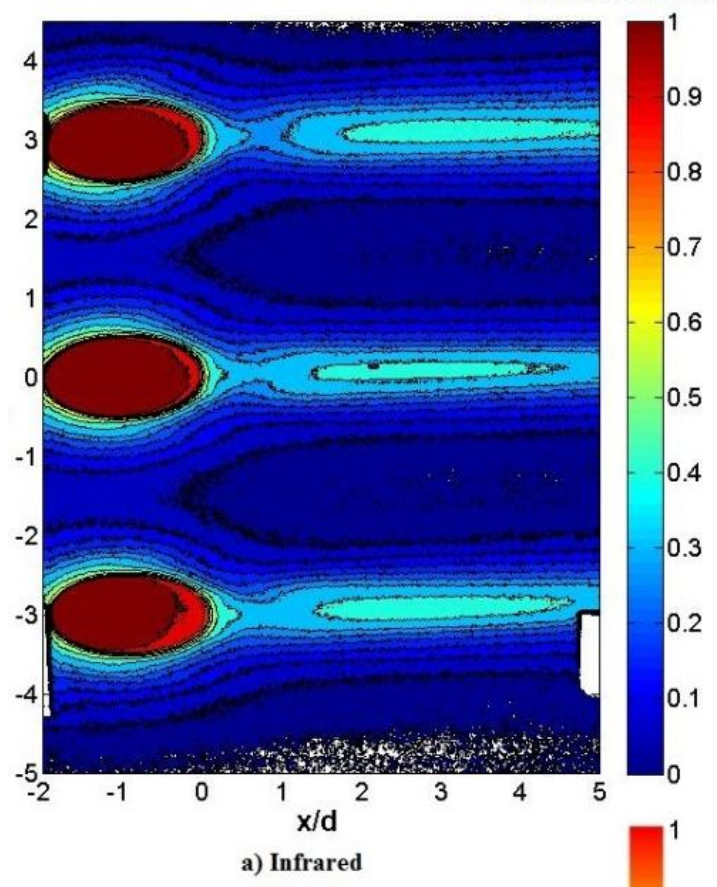

a) Infrared
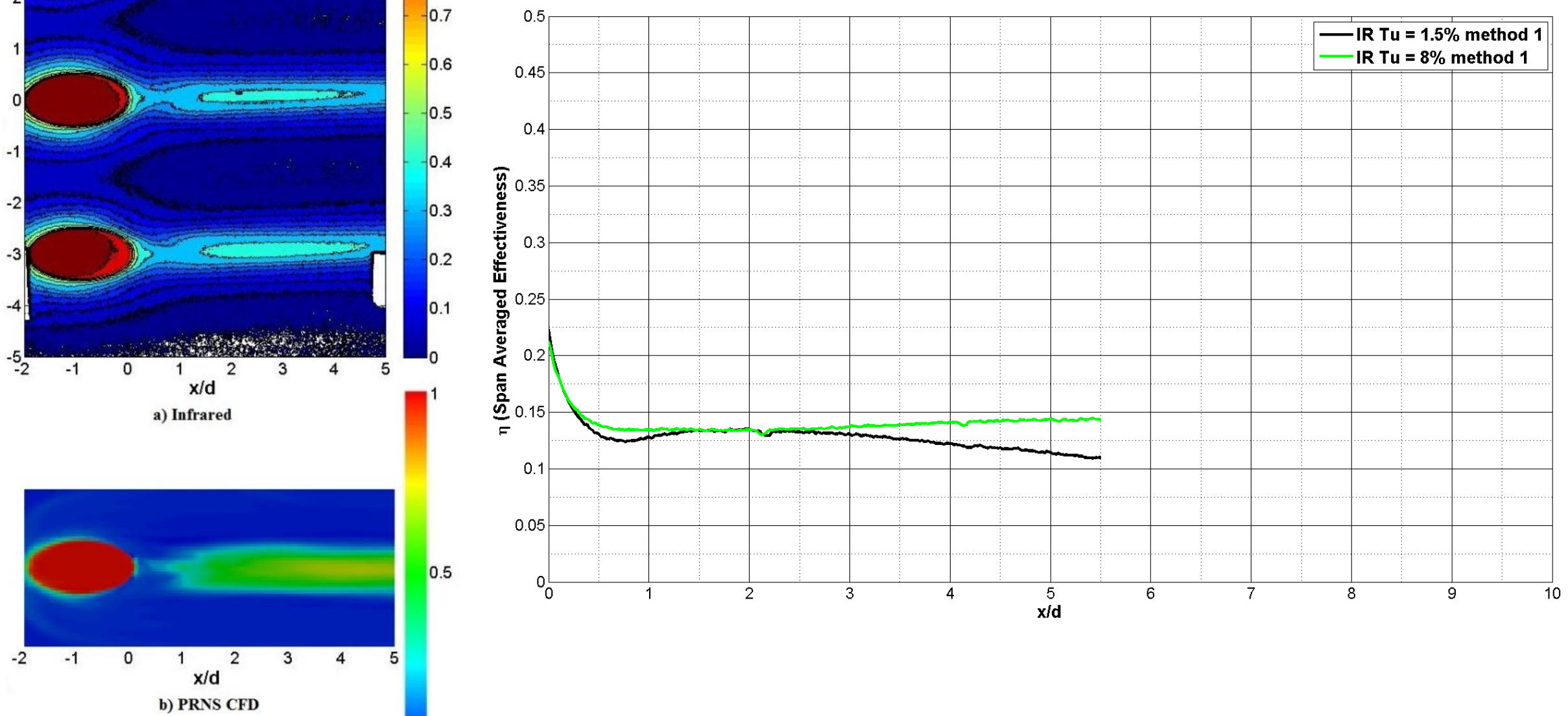


\section{Flowfield Results $-M=1.0$}

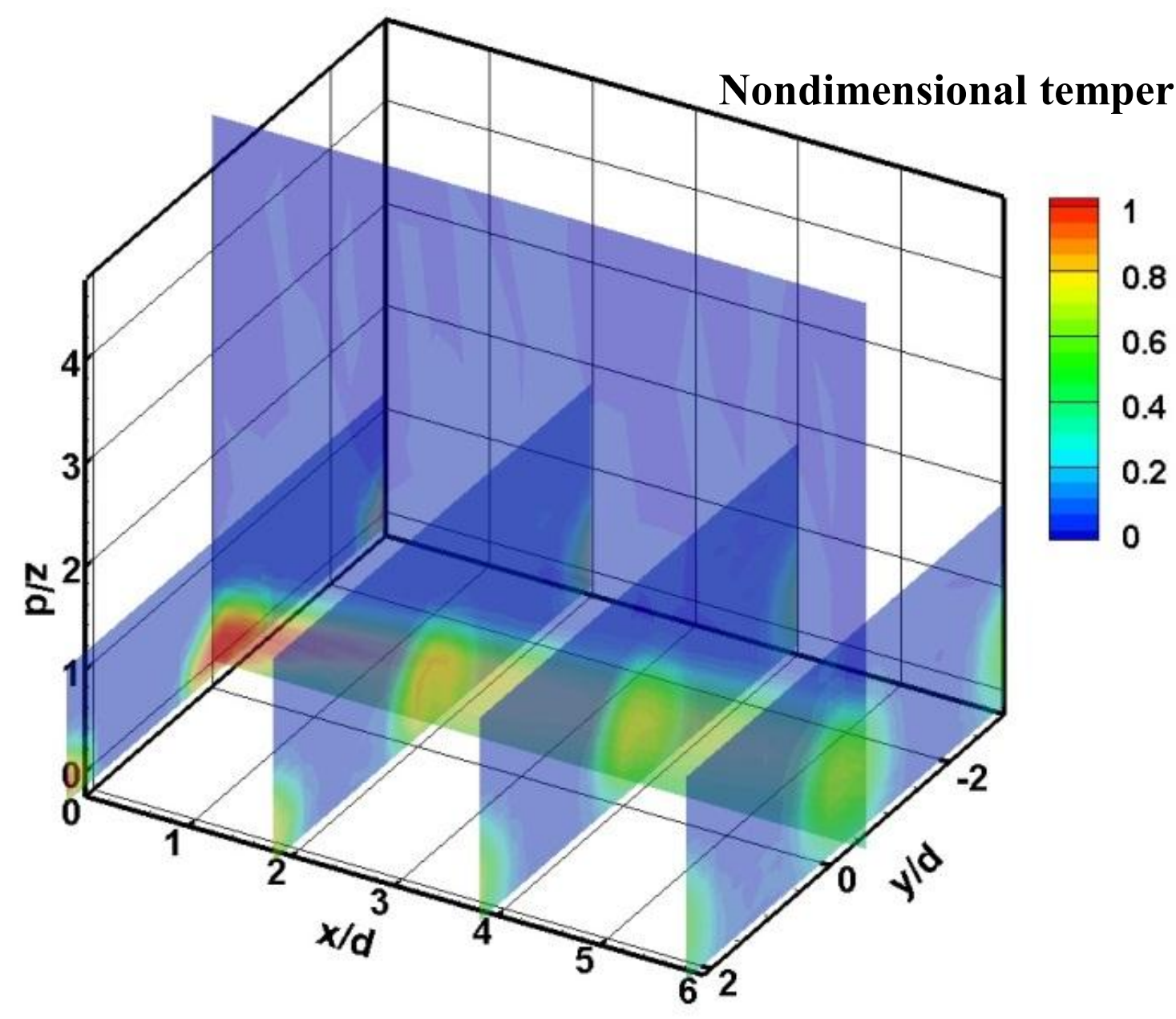


Flowfield Results $-M=1.0$
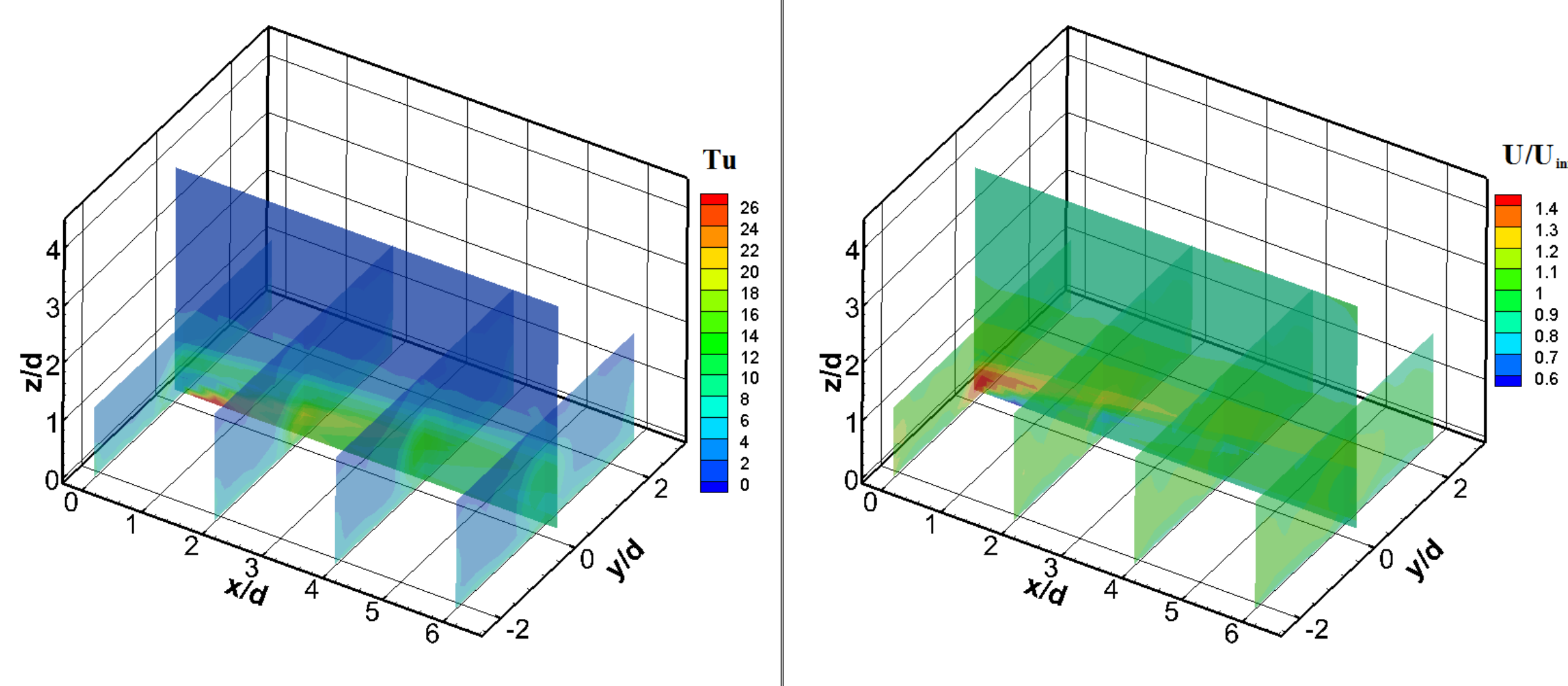


\section{Flowfield Results $-M=1.0$}
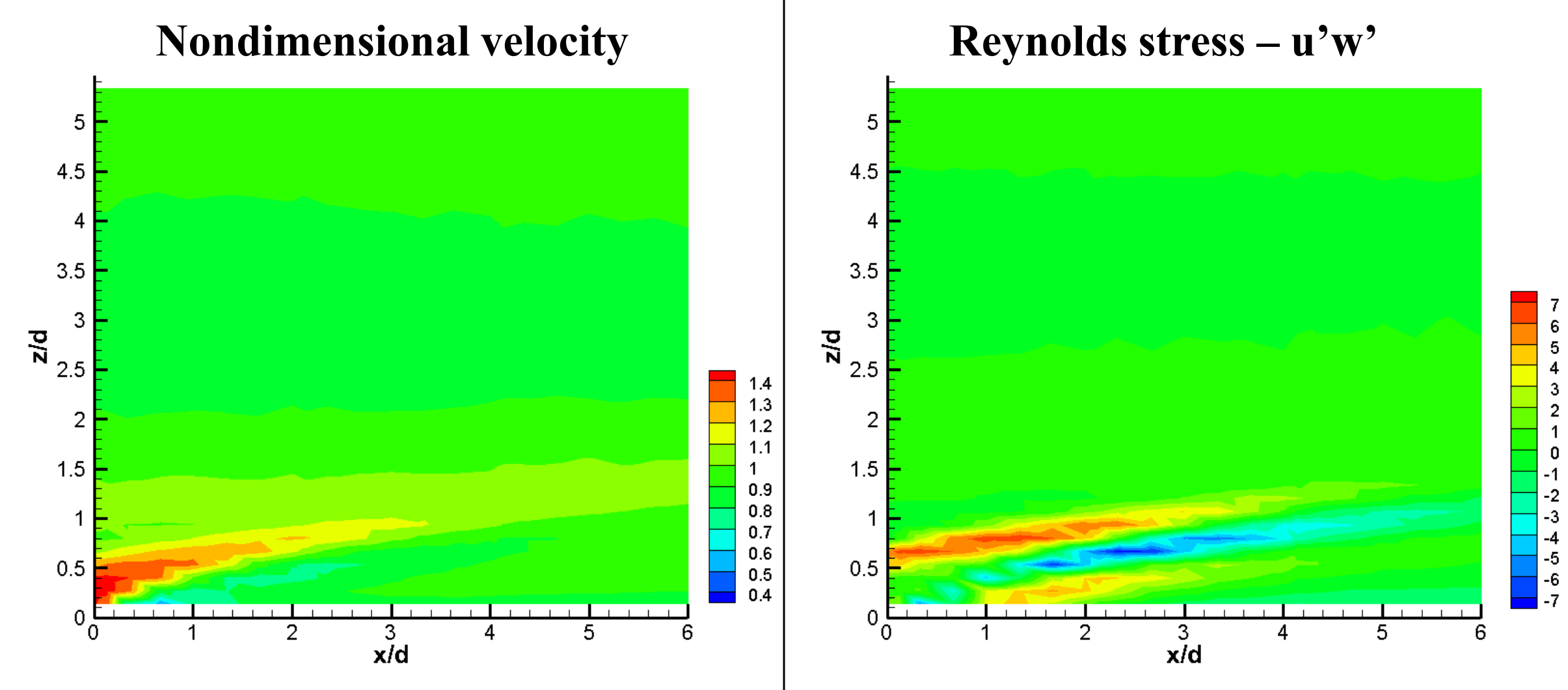


\section{Flowfield Results $-M=1.0$}

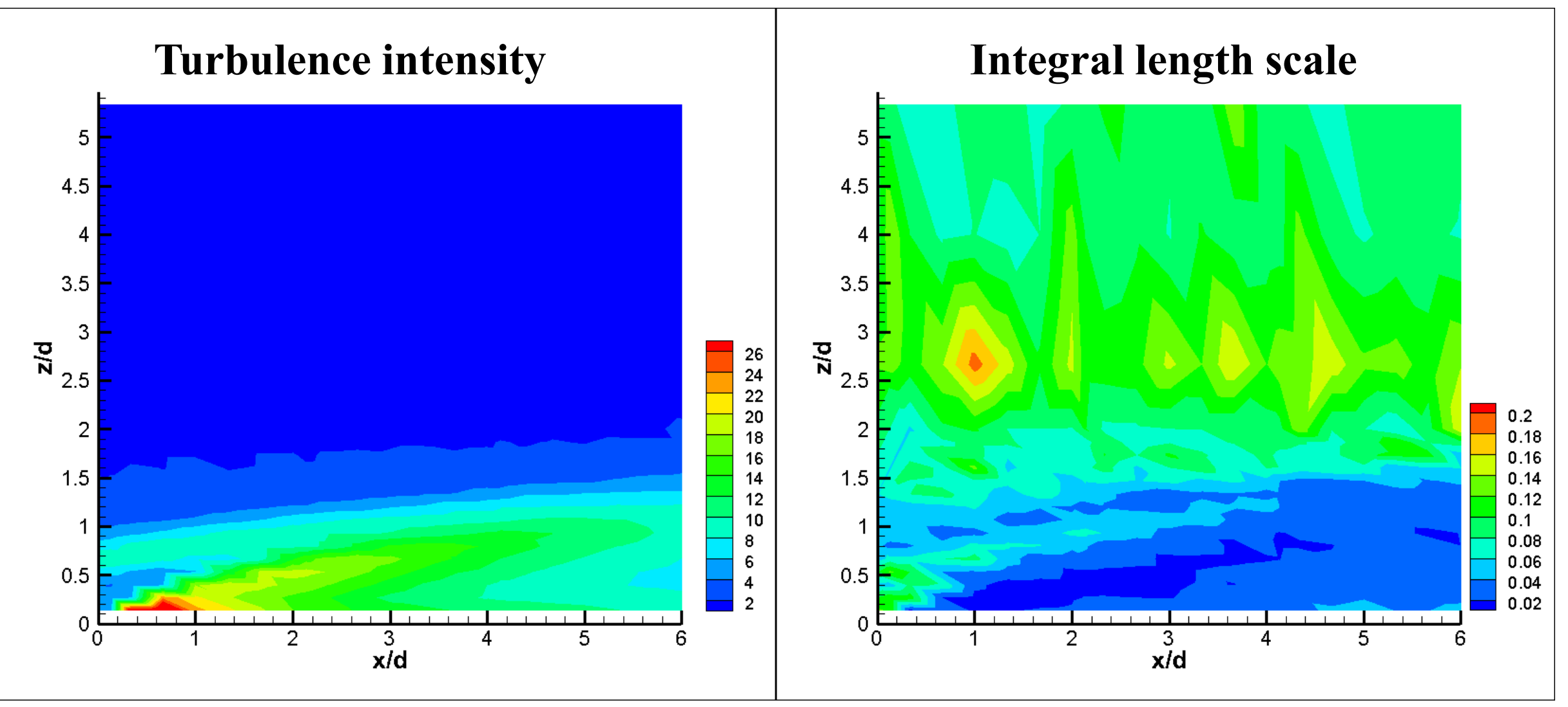




\section{Effectiveness Results $-M=2.0$}

Film effectiveness
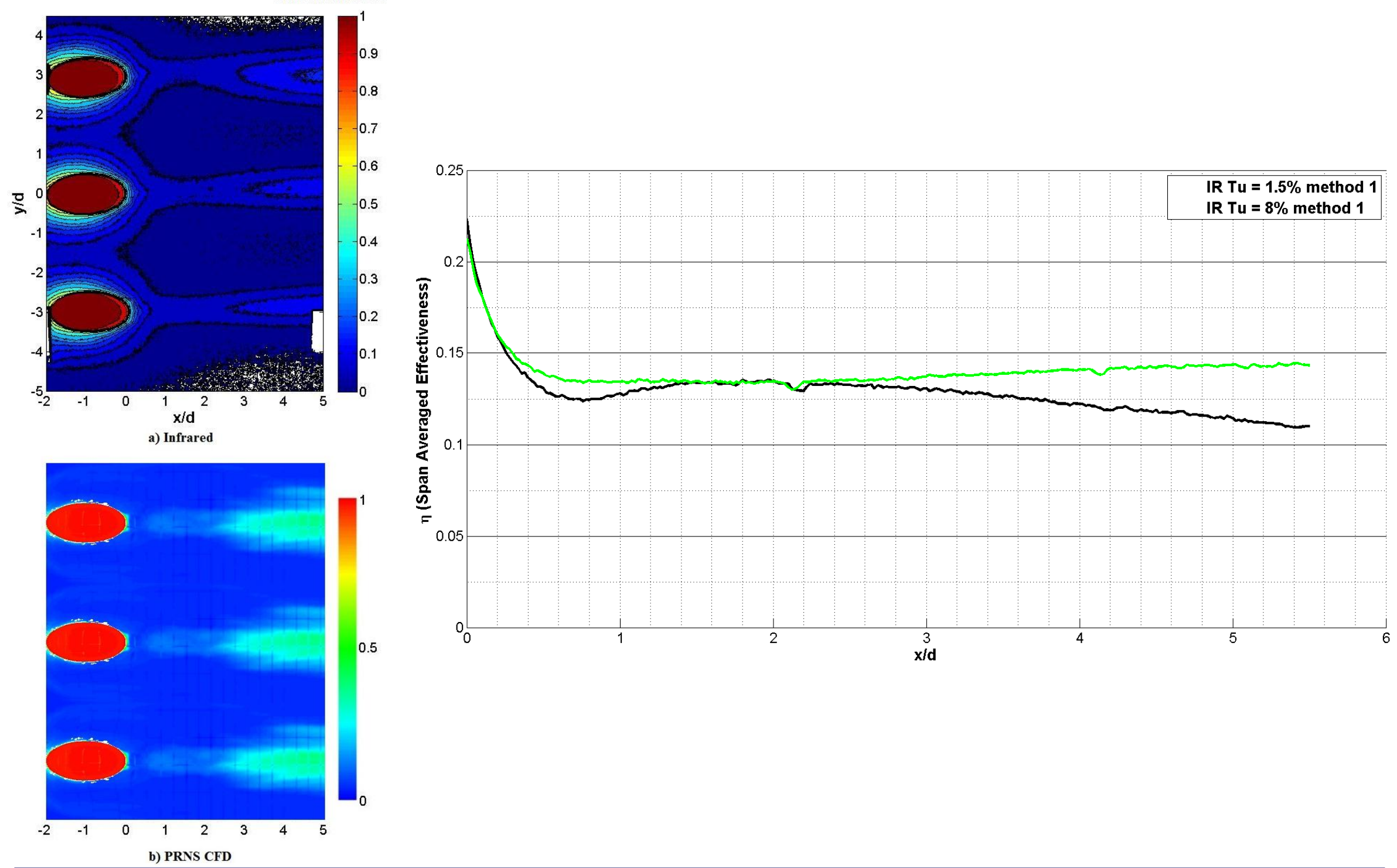


\section{Flowfield Results $-\mathrm{M}=2.0$}

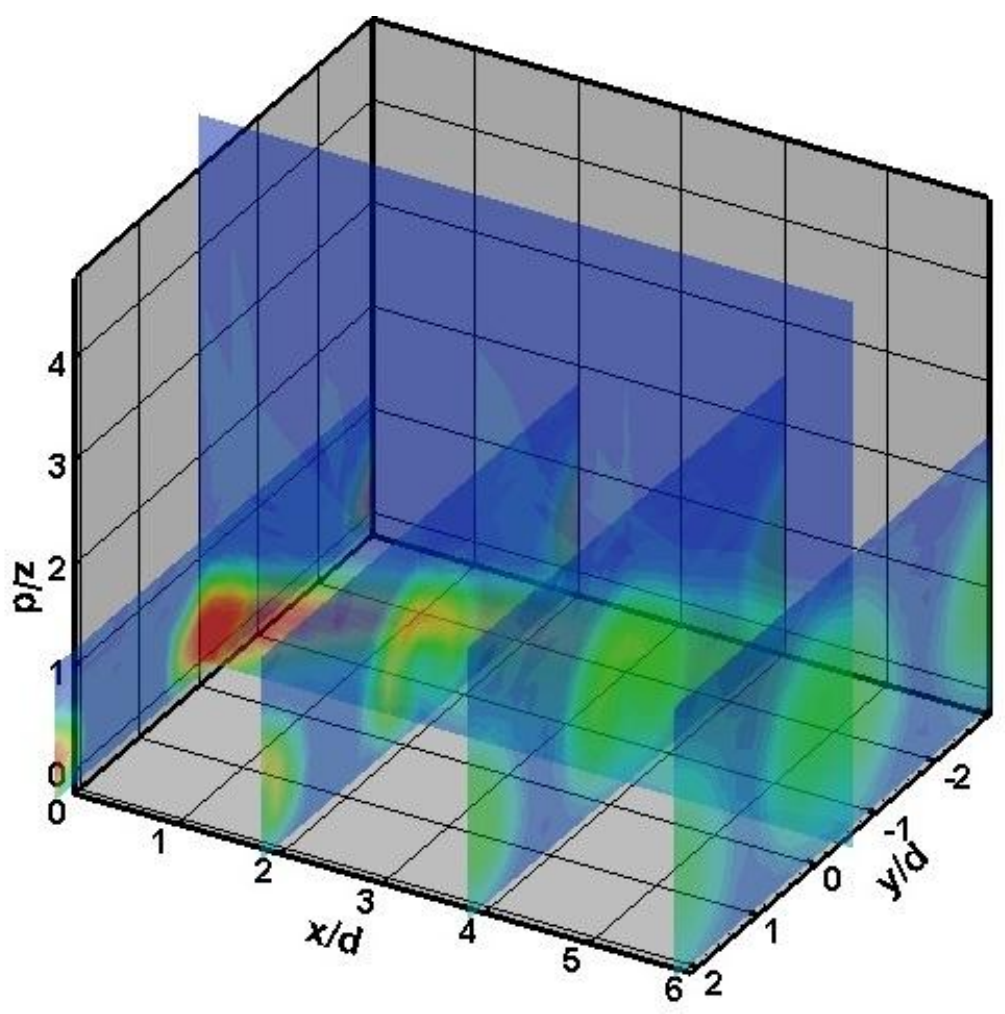

Thermocouple survey

\section{Nondimensional temperature}

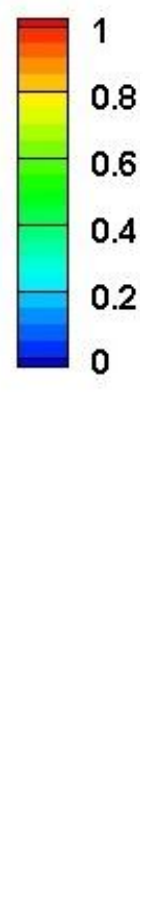

TFNS 
Flowfield Results $-M=2.0$

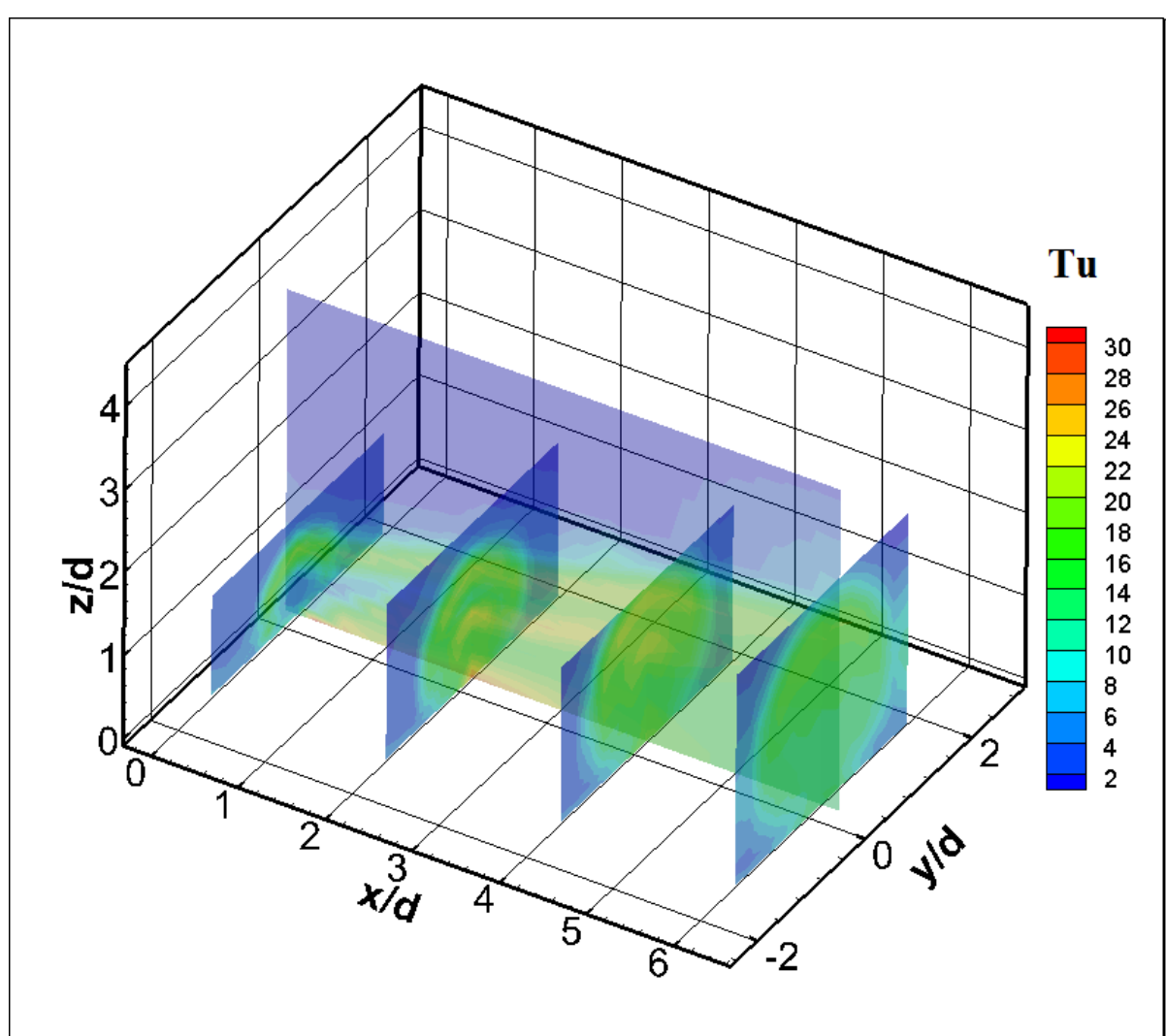

a

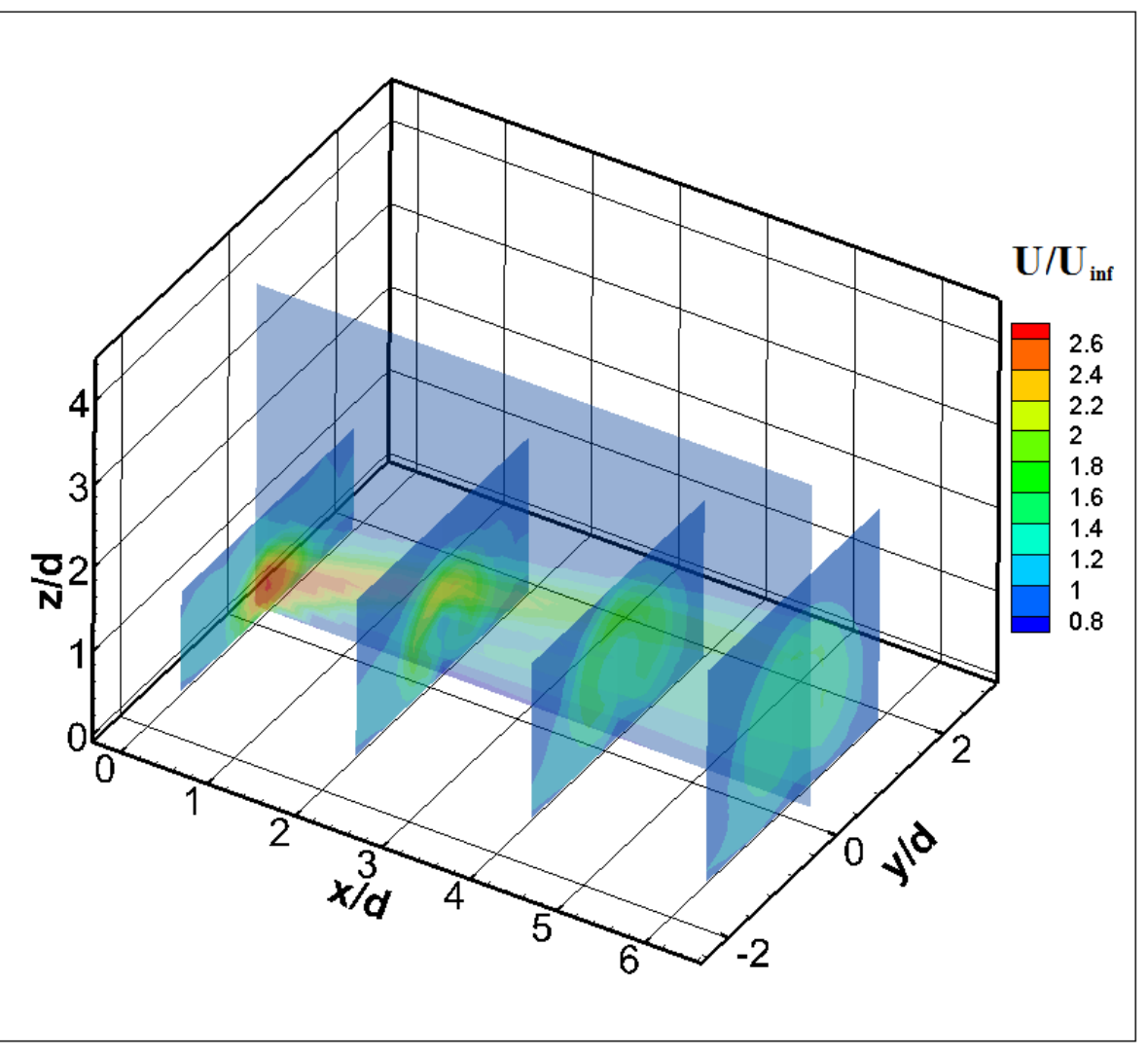

b 


\section{Flowfield Results $-\mathrm{M}=2.0$}
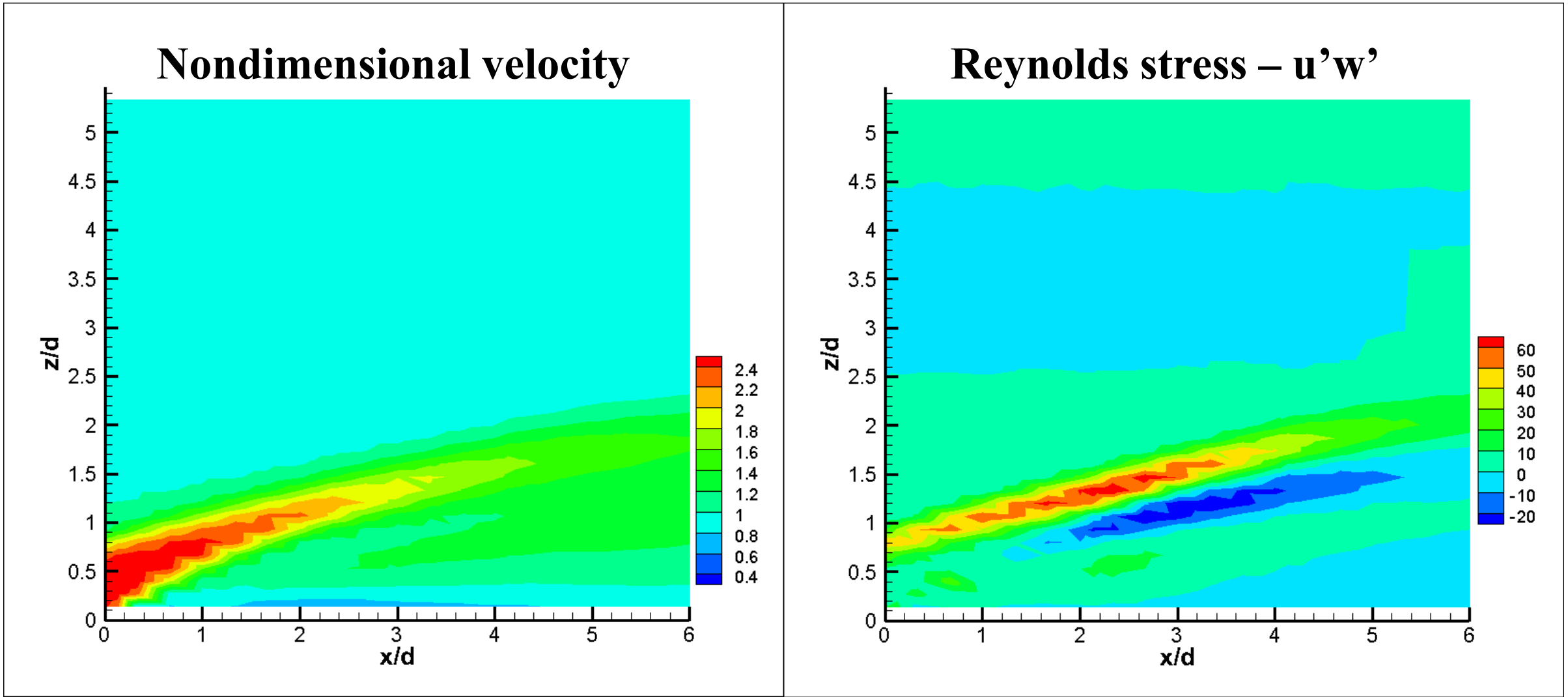


\section{Flowfield Results $-\mathrm{M}=2.0$}
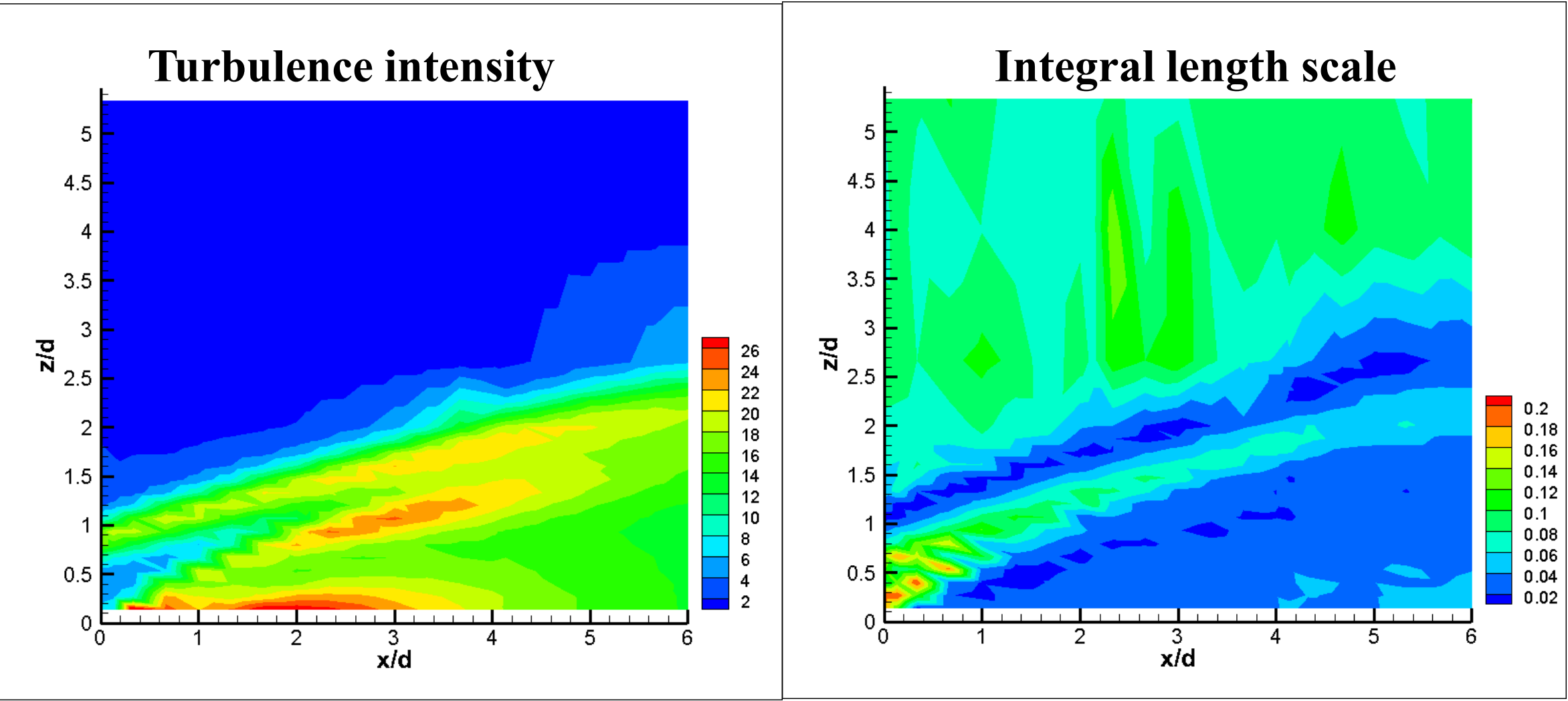


\section{Comparison to Literature}

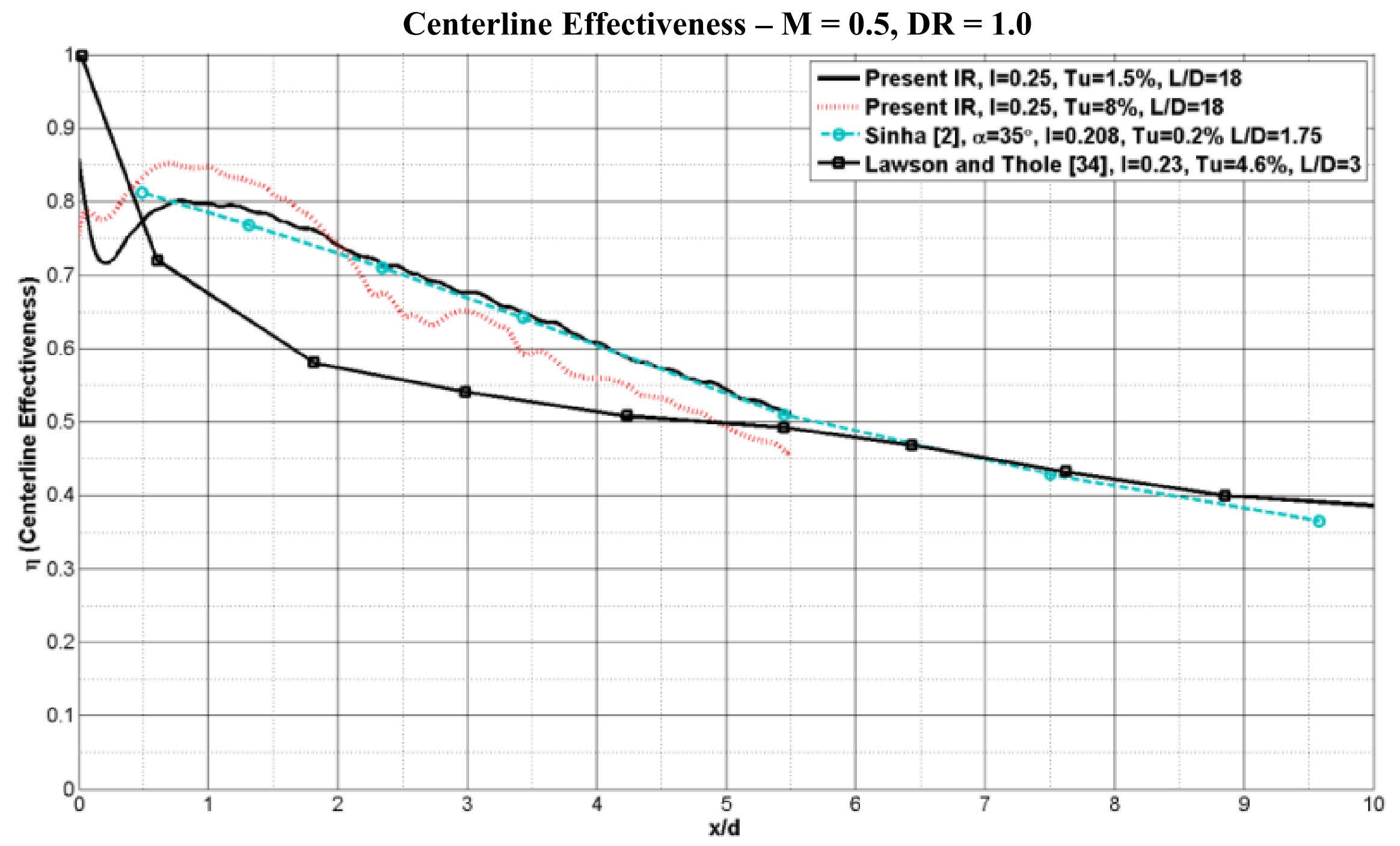




\section{Comparison to Literature}

\section{Centerline Effectiveness $-\mathrm{M}=\mathbf{1 . 0}, \mathrm{DR}=\mathbf{1 . 0}$}

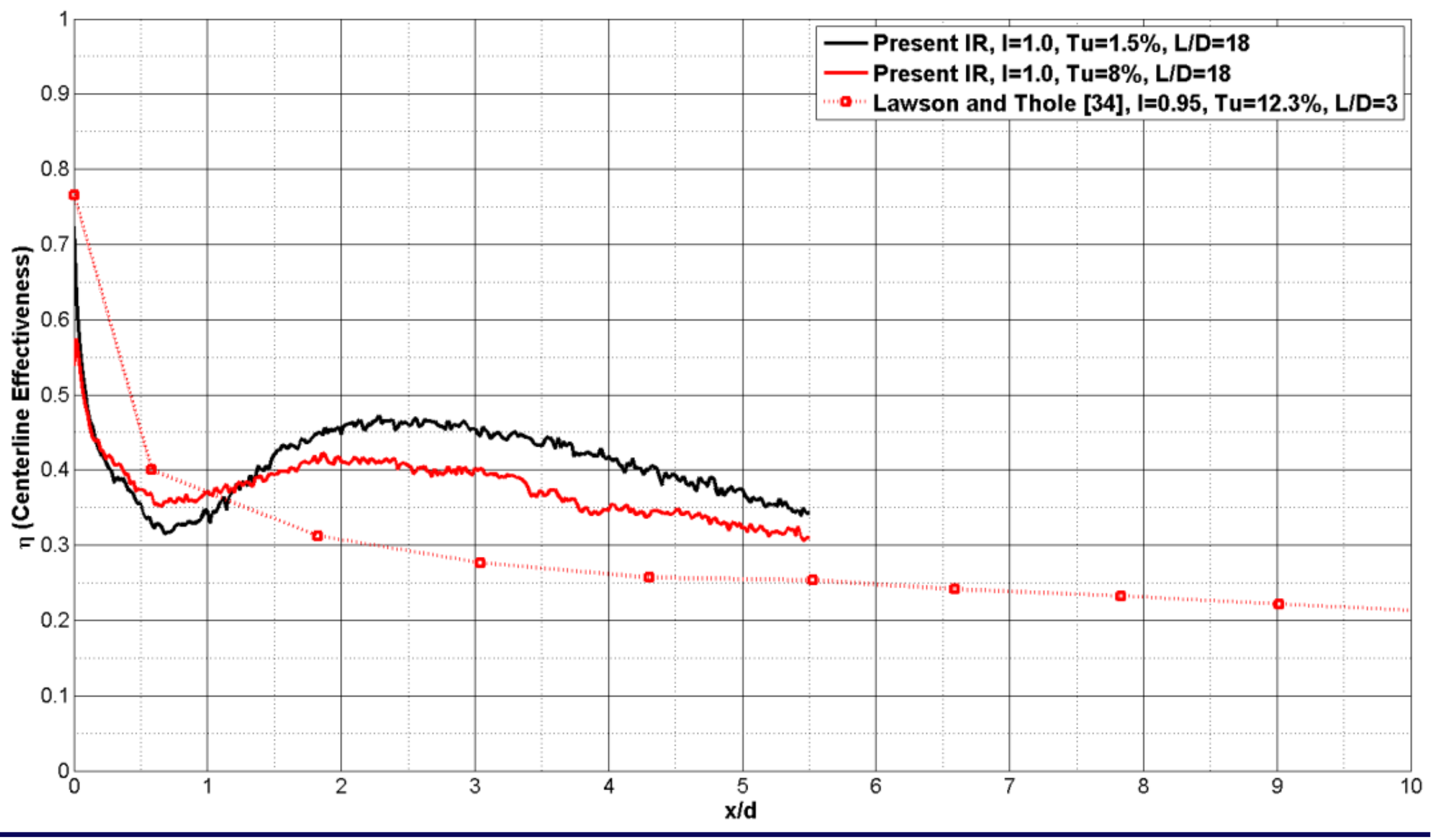




\section{Conclusions}

- K-H structures and hairpin vortices observed in TFNS

- Correlated to change in effectiveness levels on surface

- Indicate a method to improve effectiveness by controlling the breakup of the $\mathrm{K}-\mathrm{H}$ structures

- PIV and Schlieren measurements taken to identify mechanism of breakup and influence of blowing ratio and density ratio on vortex zones

- Dataset allows for simplified modeling of film cooling for CFD development 


\section{Backup Slides}




\section{Fixed Wing Targets}

\begin{tabular}{|c|c|c|c|}
\hline \multirow{2}{*}{$\begin{array}{l}\text { TECHNOLOGY } \\
\text { BENEFITS* }\end{array}$} & \multicolumn{3}{|c|}{$\begin{array}{c}\text { TECHNOLOGY GENERATIONS } \\
\text { (Technology Readiness Level = 4-6) }\end{array}$} \\
\hline & $\mathrm{N}+1$ (2015) & $\mathrm{N}+2\left(2020^{\star \star}\right)$ & $\mathrm{N}+3(2025)$ \\
\hline $\begin{array}{c}\text { Noise } \\
\text { (cum margin rel. to Stage 4) }\end{array}$ & $-32 \mathrm{~dB}$ & $-42 \mathrm{~dB}$ & $-71 \mathrm{~dB}$ \\
\hline $\begin{array}{l}\text { LTO NOx Emissions } \\
\text { (rel. to CAEP 6) }\end{array}$ & $-60 \%$ & $-75 \%$ & $-80 \%$ \\
\hline $\begin{array}{l}\text { Cruise NOx Emissions } \\
\text { (rel. to } 2005 \text { best in class) }\end{array}$ & $-55 \%$ & $-70 \%$ & $-80 \%$ \\
\hline $\begin{array}{l}\text { Aircraft Fuel/Energy Consumption } \\
\text { (rel. to } 2005 \text { best in class) }\end{array}$ & $-33 \%$ & $-50 \%$ & $-60 \%$ \\
\hline
\end{tabular}

* Projected benefits once technologies are matured and implemented by industry. Benefits vary by vehicle size and mission. $\mathrm{N}+1$ and $\mathrm{N}+3$ values are referenced to a 737-800 with CFM56-7B engines, $\mathrm{N}+2$ values are referenced to a 777-200 with GE90 engines

** ERA's time-phased approach includes advancing "long-pole" technologies to TRL 6 by 2015

$\ddagger \mathrm{CO}_{2}$ emission benefits dependent on life-cycle $\mathrm{CO}_{2 \mathrm{e}}$ per $\mathrm{MJ}$ for fuel and/or energy source used 


\section{NASA Aeronautics Programs}

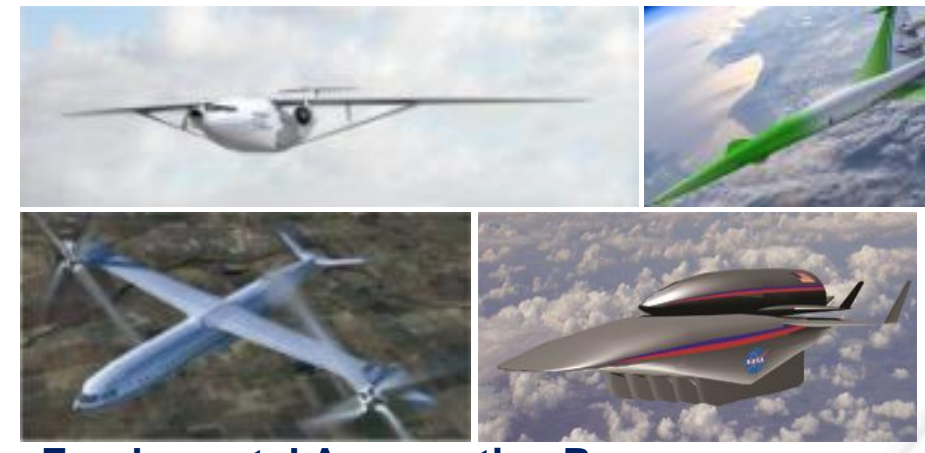

Fundamental Aeronautics Program

Conduct fundamental research that will produce innovative concepts, tools, and technologies to enable revolutionary changes for vehicles that fly in all speed regimes.
Conduct research at an integrated system-level on promising concepts and technologies and explore/assess/demonstrate the benefits in a relevant environment
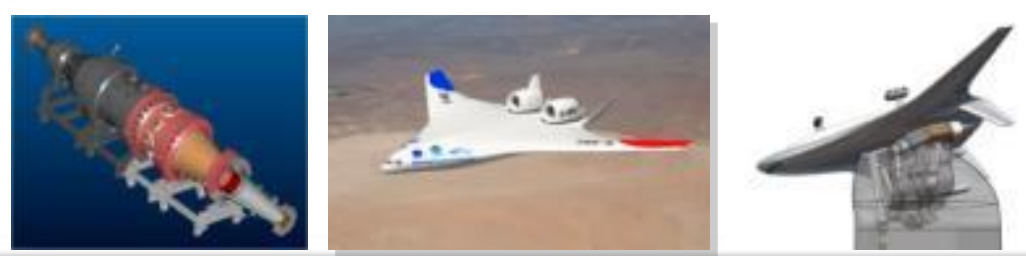

Integrated

Systems Research Program

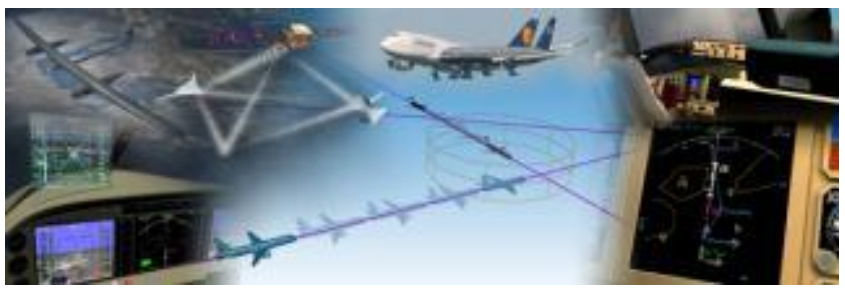

Airspace Systems Program

Directly address the fundamental ATM research needs for NextGen by developing revolutionary concepts, capabilities, and technologies that will enable significant increases in the capacity, efficiency and flexibility of the NAS.
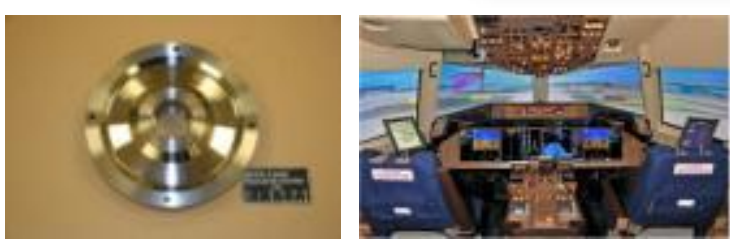

\section{Aviation Safety Program}

Conduct cutting-edge research that will produce innovative concepts, tools, and technologies to improve the intrinsic safety attributes of current and future aircraft.
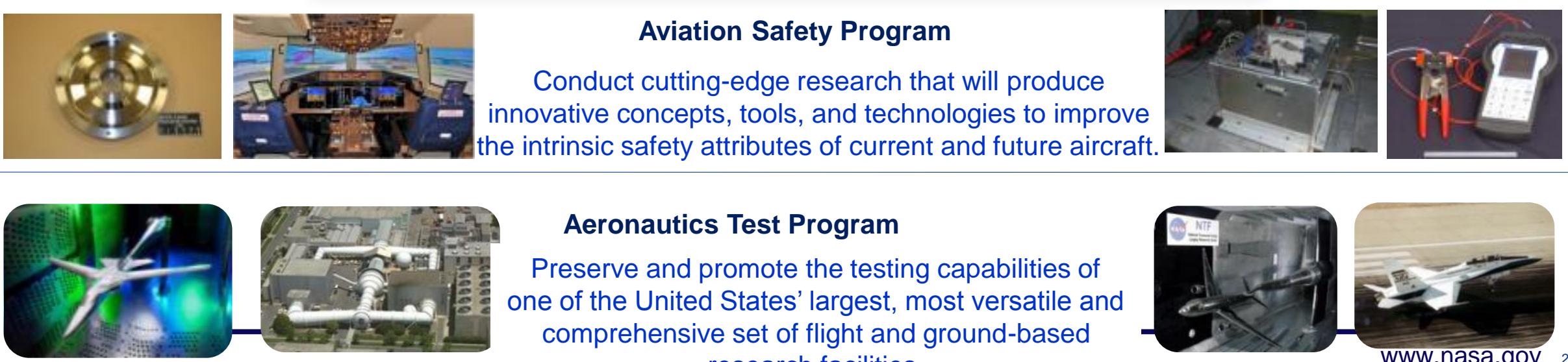

\section{Aeronautics Test Program}

Preserve and promote the testing capabilities of one of the United States' largest, most versatile and comprehensive set of flight and ground-based research facilities.

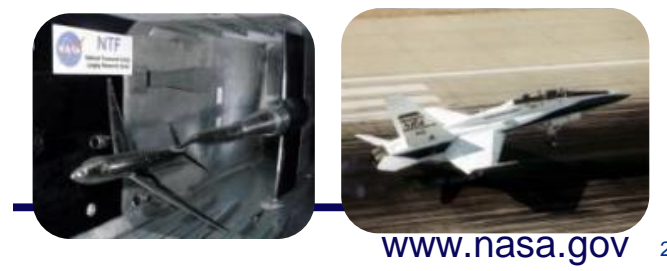




\section{FA Program Organization Structure}

\section{Fundamental Aeronautics Program Office}

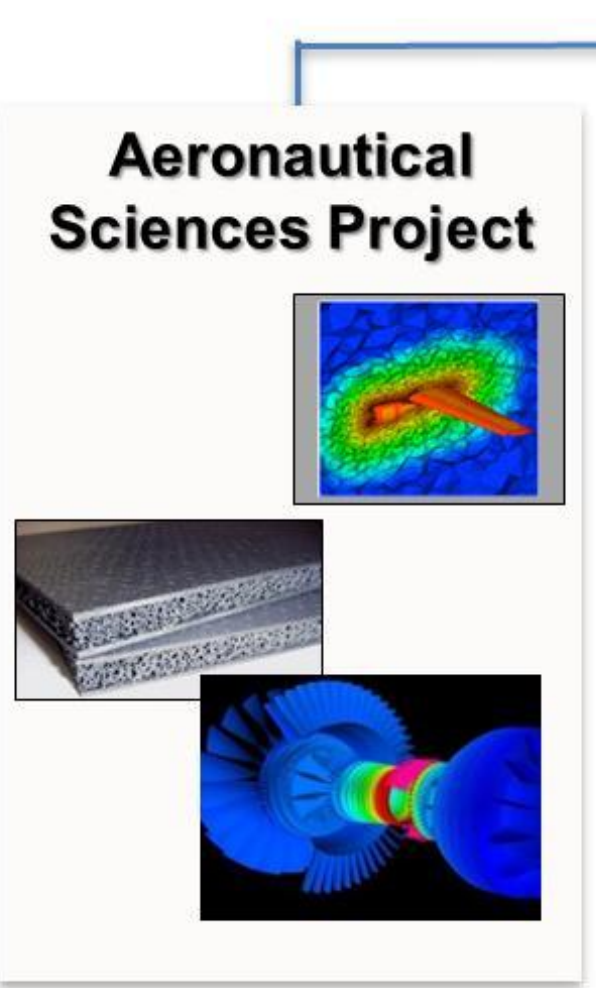

Aeronautical Sciences (AS) Enable fast, efficient design \& analysis of advanced aviation systems from first principles through physics-based tools, methods, \& cross-cutting technologies.

\section{Fixed Wing Project}
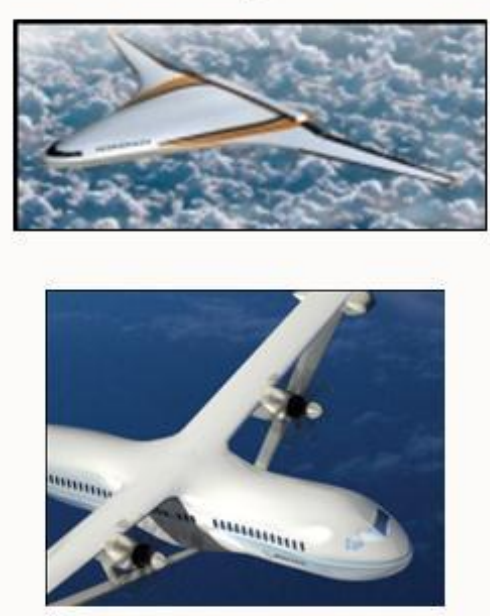

Fixed Wing (FW)

Explore \& develop technologies and concepts for improved energy efficiency \& environmental compatibility of fixed wing, subsonic transports

\section{Rotary Wing} Project
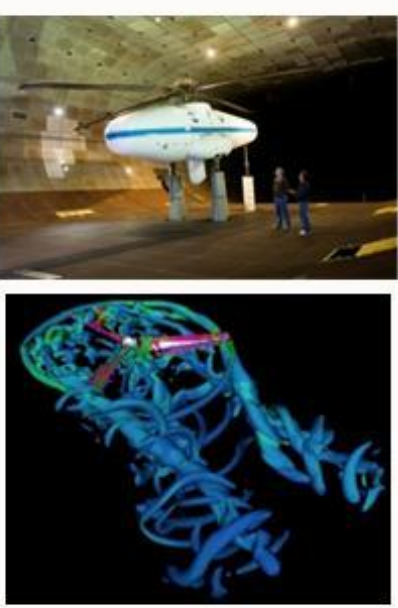

Rotary Wing (RW)

Enable radical changes in the transportation system through advanced rotary wing vehicles concepts \& capabilities.
High Speed Project

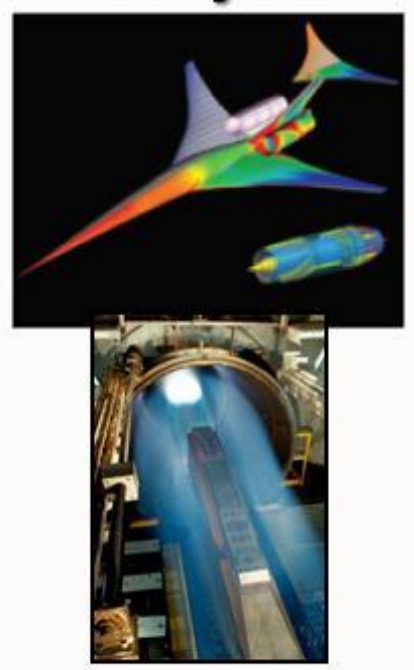

High Speed (HS)

Enable tools \&technologies and validation capabilities necessary to overcome environmental \& performance barriers to practical civil supersonic airliners. 


\section{N2A Turbofan - HPT Cooling Schematic}

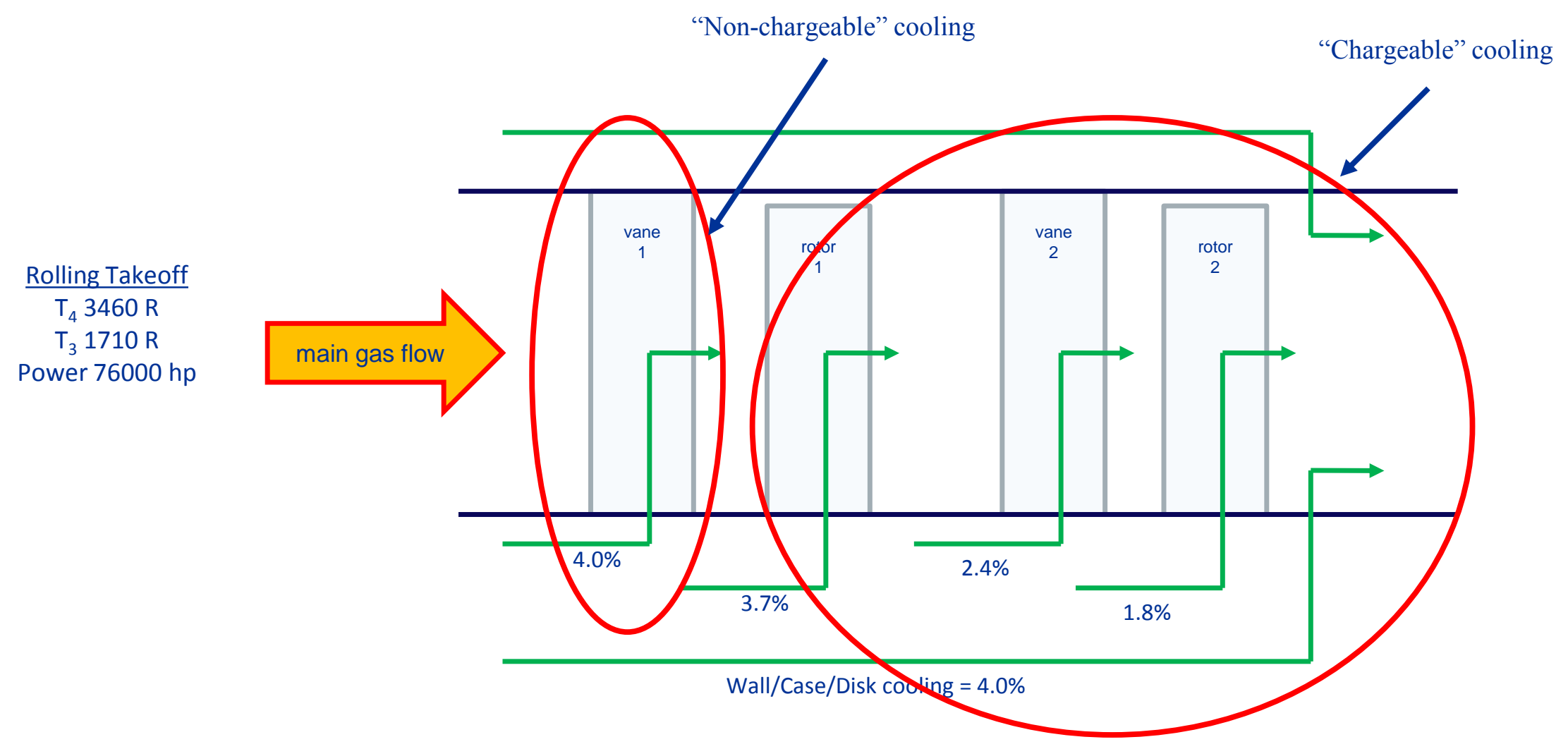

- Cooling levels defined at max. cycle temperatures (RTO for subsonic engines)

- Non-chargeable cooling flow has little/no impact on cycle performance

- All flow available to perform work through HPT rotors

- Further downstream flow is injected, more penalizing

- Penalty mitigated somewhat due to temperature decrease through machine 